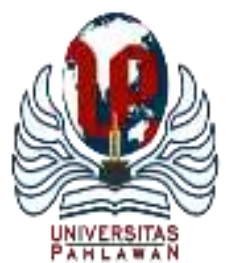

Edukatif : Jurnal Ilmu Pendidikan Volume 3 Nomor 6 Tahun 2021 Halm 5035 - 5042

EDUKATIF: JURNAL ILMU PENDIDIKAN

Research \& Learning in Education

https://edukatif.org/index.php/edukatif/index

\title{
Kearifan Lokal Sunda dalam Kegiatan Rebo Nyunda dan Potensinya untuk Tujuan Wisata Pendidikan
}

\author{
Imas Kurniawaty $^{1 凶}$, Asep Dahliyana ${ }^{2}$, Aiman Faiz ${ }^{3}$ \\ Universitas Pendidikan Indonesia, Indonesia ${ }^{1,2}$ \\ Universitas Muhammadiyah Cirebon, Indonesia ${ }^{3}$ \\ E-mail : $\underline{\text { i.kurniawaty@upi.edu }}{ }^{1}, \underline{\text { asep_dahly@upi.edu }}{ }^{2}, \underline{\text { aimanfaiz@umc.ac.id }}^{3}$
}

\begin{abstract}
Abstrak
Kearifan lokal merupakan hubungan yang baik antara manusia, alam, dan lingkungan di suatu daerah yang dipengaruhi oleh budayanya. Dalam konteks perkembangan untuk mempertahankan budaya lokal tersebut, salah satunya dapat dilakukan dengan pendekatan pariwisata. Adanya kebijakan Bandung Masagi dengan program Rebo Nyunda yang diimplementasikan dalam dunia birokrasi dan sekolah dapat dikembangkan menjadi wisata baru untuk memperkenalkan budaya sunda. Pendekatan yang digunakan untuk memperoleh data yaitu kualitatif dengan metode studi kasus. Hasil Penelitian mengilustrasikan bahwa program Rebo Nyunda yang diimplementasikan di sekolah dapat dijadikan wisata budaya dengan cara melengkapi kekurangan program yang cenderung formal dan kaku. Hal ini penting untuk meningkatkan daya tarik untuk masyarakat luar dalam mengenal kearifan lokal urang Sunda melalui lembaga pendidikan dengan lebih memperkenalkan simbol, bahasa, tata cara perilaku, dan permainan anak Sunda.
\end{abstract}

Kata Kunci: Kearifan lokal, rebo nyunda, wisata pendidikan.

\section{Abstract}

Local wisdom is a good relationship between humans, nature, and the environment in an area influenced by culture. In the context of developments to maintain the local culture, one can be done with a tourism approach. The policy of Bandung Masagi with Rebo Nyunda program implemented in the world of bureaucracy and schools can be developed into a new tour to introduce Sundanese culture. The approach used to acquire data is qualitative with case study methods. The results illustrate that the Rebo Nyunda program implemented in schools can be used as a cultural tour by complementing the shortage of programs that tend to be formal and rigid. It is important to increase the appeal for the outside community in getting to know the local wisdom of Sundanese through educational institutions with more introducing symbols, languages, behavioral ordinances, and games of Sundanese children.

Keywords: Local wisdom, rebo nyunda, educational tourism.

Copyright (c) 2021 Imas Kurniawaty, Asep Dahliyana, Aiman Faiz

$\triangle$ Corresponding author

Email : i.kurniawaty@upi.edu

DOI : https://doi.org/10.31004/edukatif.v3i6.1538 
5036 Kearifan Lokal Sunda dalam Kegiatan Rebo Nyunda dan Potensinya untuk Tujuan Wisata PendidikanImas Kurniawaty, Asep Dahliyana, Aiman Faiz

DOI: https://doi.org/10.31004/edukatif.v3i6.1538

\section{PENDAHULUAN}

Bandung dikenal sebagai pusat pendidikan di Tatar Sunda membuat sebuah inovasi dalam dunia pendidikan, yaitu dengan menghadirkan program pendidikan karakter berbasis kearifan lokal yang bertajuk "Bandung Masagi". Kearifan lokal berarti hubungan yang baik antara manusia, alam, dan lingkungan di suatu daerah yang juga dipengaruhi oleh budayanya. Fenomena globalisasi dan modernisasi saat ini sering membuat budaya cepat dilupakan (Mawarni, H., Suwandi, S., \& Supriyadi, 2019). Baik secara sadar maupun tidak sadar nilai budaya tersebut (kearifan lokal) dikhawatirkan akan punah ditengah modernisasi dan perkembangan zaman (Faiz et al., 2020). Oleh karena itu perlu dilestarikan, salah satunya kebudayaan dan nilai-nilai kehidupan sunda. Bandung Masagi ini diresmikan oleh Mendikbud saat itu bersama Walikota Bandung dan Kepala Dinas Pendidikan Kota Bandung pada tahun 2016 lalu. Mendikbud mengapresiasi dan menjadikan Bandung Masagi sebagai program percontohan tentang pendidikan karakter yang berbasis pada kearifan budaya lokal di Indonesia, karena sejalan dengan revolusi mental yang dicanangkan pemerintah pusat (DetikNews).

Program Pendidikan karakter berbasis kearifan local kota Bandung diberi nama Bandung Masagi. Kata "Masagi" berasal dari Bahasa Sunda yang artinya sagala bisa, seimbang/ajeg/kokoh kearah kesempurnaan. Dalam makna yang mendalam, masagi kurang lebih diartikan sebagai sikap yang mengarah ke upaya untuk mencari kesempurnaan-kesatupaduan yang seimbang untuk menghindari cara pandang yang tidak utuh baik dalam melihat masalah maupun dalam membuat keputusan. Model pendidikan karakter Bandung Masagi dikenalkan sebagai konsep PLS (Pengenalan Lingkungan Sekolah) dalam upaya memperkuat implementasi Permendikbud 18 tahun 2016. Didalamnya terdapat empat prinsip yang ada pada pendidikan karakter Bandung Masagi. Pertama, silih asih, bermakna saling mengasihi dengan memperlihatkan kasih sayang yang tulus. Kedua, silih asah, bermakna saling mencerdaskan, saling memperluas wawasan dan pengalaman lahir batin. Ketiga, silih asuh, bermakna saling membimbing, mengayomi, membina, menjaga, mengarahkan dengan seksama agar selamat lahir dan batin. Keempat, silih wawangi, bermakna saling menghubungan hal yang positif untuk saling memberikan hal yang positif (Suryalaga, 1993). Dari empat prinsip tersebut lahir empat program, cinta agama sebagai dasar dan kompas moral. Kedua, jaga budaya, sehingga lahirlah program

Rebo Nyunda. Ketiga, Bela negara, dan keempat cinta lingkungan (Https://Jabar.Tribunnews.Com/2016/07/19/Ini-Harapan-Emil-Soal-Bandung-Masagi-Dalam-KonsepPendidikan-Karakter).

Rebo Nyunda adalah sebuah gerakan yang dilakukan oleh pemerintah daerah di Jawa Barat sebagai upaya untuk melestarikan nilai-nilai kehidupan dan budaya di wilayahnya. Gerakan ini berasal dari kekhawatiran banyak pihak terhadap semakin tergerusnya nilai-nilai kehidupan dan budaya asli Indonesia oleh pengaruh dari luar. Perkembangan kehidupan dalam masyarakat Indonesia menunjukkan pengaruh budaya asing semakin lama semakin menggeser nilai-nilai tradisional (Https://Jabar.Tribunnews.Com/2016/07/19/IniHarapan-Emil-Soal-Bandung-Masagi-Dalam-Konsep-Pendidikan-Karakter).

Kegiatan Rebo Nyunda adalah sebuah program dari Pemerintah Kota Bandung sebagai bagian dari harihari tematik yang berlaku di Kota Bandung. Program ini digagas oleh Walikota Bandung, Ridwan Kamil dan muncul karena adanya kekhawatiran dari segelintir masyarakat akan lunturnya kebudayaan Sunda di Jawa Barnt, khususnya di Kota Bandung. Dengan demikian, program ini merupakan salah satu program untuk melestarikan Budaya Sunda. Program ini merupakan salah satu usaha Pemerintah Kota Bandung untuk mengimplementasikan Peraturan Daerah (Perda) Nomor 2 Tahun 2012 yang menyebutkan bahwa setiap hari Rabu warga Kota Bandung diharuskan berkomunikasi dalam Bahasa Sunda dan Perda Kota Bandung Nomor 9 Tahun 2012 tentang Penggunaan, Pemeliharaan, dan Pengembangan Bahasa, Sastra dan Aksara Sunda (Mufti, 2012).Dalam kegiatan ini, masyarakat Kota Bandung khususnya pelajar juga dihimbau menggunakan pakaian adat Sunda yakni kebaya dan kain batik sebagai bawahan bagi perempuan, serta iket kepala batik dan 
5037 Kearifan Lokal Sunda dalam Kegiatan Rebo Nyunda dan Potensinya untuk Tujuan Wisata PendidikanImas Kurniawaty, Asep Dahliyana, Aiman Faiz

DOI: https://doi.org/10.31004/edukatif.v3i6.1538

bila memungkinkan menggunakan pangsi bagi laki-laki. Selain iket kepala, para laki-laki juga dapat menambahkan hiasan kujang sebagai penghias iket tersebut. Bersamaan dengan menggunakan pakaian Sunda, setiap hari Rabu juga seluruh warga Bandung diharapkan menggunakan Bahasa Sunda untuk berkomunikasi dengan orang lain. Program Rebo Nyunda ini mulai diberlakukan di Kota Bandung pada tanggal 6 November 2013 ((Http://Bandungjuara.Com).

\section{METODE PENELITIAN}

Penelitian ini menggunakan pendekatan kualitatif yaitu pendekatan yang lebih menekankan pada pemaknaan dan konteks pendeskripsian lebih bersifat rich and thick description (Creswell, 2010), yaitu bersifat kaya dan tebal, holistik, emik dan etik. Metode penelitian yang digunakan ialah metode studi kasus. Yin (2002)menyatakan bahwa studi kasus adalah suatu inkuiri empiris yang menyelidiki fenomena di dalam konteks kehidupan nyata bilamana, batas-batas antara fenomena dan konteks tak tampak dengan tegas, dan dimana multisumber bukti dimanfaatkan". Pengumpulan data dilakukan melalui dokumentasi dan studi literatur dimana Teknik ini dilakukan dengan cara membaca, mempelajari dan mengkaji literatur-literatur yang berhubungan dengan kearifan lokal sunda dalam kegiatan rebo nyunda dan potensinya untuk tujuan wisata Pendidikan. Pengkajian literatur untuk kepentingan penelitian ini adalah berupa lietratur teknis dan literatur non-teknis (Strauss, A., Corbin, 2009).

\section{HASIL DAN PEMBAHASAN PENELITIAN}

Kearifan lokal nilai budaya local yang dapat dimanfaatkan untuk mengatur tatanan kehidupan masyarakat secara arif atau bijaksana (Sibarani, 2014). Hal ini menekankan bahwa nilai budaya luhur yang digunakan untuk kebijaksaan atau kearifan menata kehidupan sosial. Kebijaksaan atau kearifan ini pun harus dilihat dari kematangan masyarakat dalam sikap dan perilaku seperti menurut Balitbang Depsos RI 2005 kearifan lokal merupakan kematangan masyarakat dalam sikap, perilaku dan cara pandang masyarakat yang kondusif didalam mengembangkan potensi dan sumer local (material maupun nonmaterial) yang dapat dijadikan sebagai kekuatan di dalam mewujudkan perubahan ke arah yang lebih baik atau positif. Kearifan lokal menjadi nilai yang memiliki filosofi hidup yang menjadi pegangan oleh masyarakat yang menjalankannya (Faiz \& Soleh, 2021). Dari pernyataan tersebut, kearifan lokal merupakan milik masyarakat yang sikap yang dan kepribadiannya matang untuk mampu mengembangakan potensi dan sumber lokal dalam melakukan perubahan ke arah yang lebih baik.

Kearifan lokal, dalam bentuk filosofi hidup, sikap, dan pedoman perilaku, akan membantu masyarakat untuk bertahan dari berbagai ancaman yang mengganggu keberadaan mereka dari bencana alam dan dinamika kehidupan. Orang Sunda, memiliki kearifan lokal yang dapat melindungi lingkungan mereka. Nilai kearifan lokal ini sangat penting untuk ditransmisikan dan ditransformasikan menjadi turis domestik dan internasional melalui ekowisata. Ekowisata dikenal sebagai pariwisata berkelanjutan, pariwisata hijau, dan edutourisme karena memiliki visi kelestarian lingkungan, aktivitas tanpa polusi, konservasi, pemberdayaan masyarakat, dan apresiasi terhadap alam dan budaya masyarakat (Maryani \& Yani, 2016). Kearifan lokal merupakan potensi budaya yang sangat strategis untuk menjadi daya tarik dalam pengembangan sektor pariwisata. Keberhasilan pariwisata berbasis kearifan lokal sangat ditentukan oleh bagaimana penerimaan masyarakat ditunjukkan oleh sikap responsif terhadap nilai-nilai budaya dan kearifan lokal. Untuk menginspirasi semakin meningkatnya peran masyarakat dalam menumbuhkan nilai-nilai kearifan lokal, diperlukan kebijakan dalam bentuk langkah-langkah dan upaya sistemik dan berkesinambungan sehingga masyarakat memiliki pemahaman yang baik tentang program pengembangan pariwisata berbasis kearifan lokal. Sehingga kearifan lokal menjadi nilai-nilai strategis dalam kehidupan masyarakat yang dapat berdampak positif pada 
5038 Kearifan Lokal Sunda dalam Kegiatan Rebo Nyunda dan Potensinya untuk Tujuan Wisata PendidikanImas Kurniawaty, Asep Dahliyana, Aiman Faiz

DOI: https://doi.org/10.31004/edukatif.v3i6.1538

pengembangan pariwisata berbasis kearifan lokal. Oleh karena itu, perlu untuk meningkatkan sosialisasi dan sinergi dengan semua pemangku kepentingan untuk mengintensifkan nilai-nilai budaya dan kearifan lokal agar pengembangan pariwisata berbasis kearifan lokal dilakukan dengan baik sehingga pengembangan pariwisata harus memberikan keamanan bagi migran, karena harmonisasi penduduk dengan kreativitas dan toleransi mereka merupakan daya tarik wisata yang menarik (Saad, 2017).

Masyarakat Indonesia beragam, majemuk, multietnis, dan multikultural. Kondisi itu berkontribusi besar dalam memecah karakter nasional. Tak perlu dikatakan bahwa pendidikan memiliki dua misi yaitu: transfer nilai dan pengetahuan. Pendidikan harus mewarisi nilai-nilai budaya bangsawan nasional, dan pada saat yang sama ia menangkal dampak negatif dari nilai-nilai budaya global. Karakter pendidikan harus mampu mempersiapkan generasi yang unggul secara intelektual dan mampu mempertahankan kepribadian dan identitas nasional (Hasanah et al., 2016).

Untuk membangun identitas nasional melalui pendidikan dapat dilakukan dengan mengembalikan pembelajaran kearifan lokal. Ciri-ciri kearifan lokal adalah: (1) berdasarkan pengalaman (2) diuji setelah penggunaan berabad-abad (3) dapat disesuaikan dengan budaya saat ini (4) disatukan dalam praktik seharihari masyarakat dan lembaga (5) yang biasa dilakukan oleh individu atau masyarakat secara keseluruhan (6) dinamis dan terus berubah (7) sangat terkait dengan sistem kepercayaan. Membangun sistem pendidikan berarti upaya terencana dalam bentuk optimalisasi komponen pendidikan (Darmadi, 2018).

Tujuan pendidikan berdasarkan kearifan lokal sesuai dengan yang telah dinyatakan dalam UU. 20 Tahun 2003 Tentang Sisdiknas Pasal 3, menyatakan bahwa: "Pendidikan nasional berfungsi untuk mengembangkan kemampuan dan membentuk karakter dan peradaban bangsa yang bermartabat dalam rangka mencerdaskan kehidupan bangsa" (Faiz et al., 2021). Pendidikan kearifan lokal adalah bagian dari budaya suatu masyarakat yang tidak dapat dipisahkan dari bahasa masyarakat itu sendiri. Kearifan lokal diturunkan dari generasi ke generasi melalui mulut ke mulut. Kearifan lokal ada dalam cerita rakyat, amsal, lagu, dan permainan orang. Kearifan lokal sebagai pengetahuan yang ditemukan oleh komunitas lokal tertentu melalui sekumpulan pengalaman dalam mencoba dan terintegrasi dengan pemahaman tentang budaya dan sifat suatu tempat. Seiring dengan perkembangan zaman seiring dengan pesatnya arus informasi dan teknologi yang terus berubah, ada kecenderungan kearifan lokal mulai terpinggirkan. Perlu disosialisasikan kepada generasi muda agar budaya kebijaksanaan tidak hilang dalam waktu. (Darmadi, 2018) Karakter pendidikan tidak diragukan lagi membutuhkan upaya terus-menerus untuk menghasilkan model pendidikan berbasis karakter dari kearifan lokal untuk masyarakat majemuk seperti Indonesia. Upaya ini diharapkan dapat membawa siswa Indonesia untuk mendapatkan keunggulan yang istimewa di tengah-tengah kontestasi budaya global (Hasanah et al., 2016).

Bahan ajar yang didasarkan pada kearifan lokal memberikan pembelajaran kontekstual sehingga mengajar siswa dengan situasi yang lebih konkret. Dengan cara ini, lebih mudah bagi siswa untuk mengembangkan ide-ide kreatif mereka dan mengekspresikannya dalam bentuk tertulis (Santosa et al., 2019). Untuk nilai-nilai kearifan lokal yang lebih optimal dalam membangun pariwisata sebagai berikut perlunya peningkatan penggalian dan penilaian nilai-nilai kearifan lokal dengan melibatkan institusi Pendidikan Tinggi dan Masyarakat Adat serta perlunya peningkatan sosialisasi nilai-nilai kearifan lokal dalam pendidikan formal (Dari Sekolah Dasar ke Sekolah Menengah Atas) dan masyarakat umum, sehingga memfasilitasi percepatan pengembangan pariwisata berbasis kearifan local (Saad, 2017). Menggunakan kearifan lokal untuk mempromosikan pariwisata melalui proses pariwisata kreatif untuk menciptakan pengembangan pariwisata berkelanjutan ditargetkan pada masyarakat. Keseimbangan harus dibuat dalam hal ekonomi, masyarakat dan lingkungan sehingga masyarakat, dengan keseimbangan ini, dapat mengembangkan pariwisata berkelanjutan (Singsomboon, 2014).

Program Rebo Nyunda yang diimplementasikan di sekolah dapat program pendidikan karakter (Faiz, 2019) dan dijadikan wisata budaya dengan cara melengkapi kekurangan program yang cenderung formal dan 
5039 Kearifan Lokal Sunda dalam Kegiatan Rebo Nyunda dan Potensinya untuk Tujuan Wisata PendidikanImas Kurniawaty, Asep Dahliyana, Aiman Faiz

DOI: https://doi.org/10.31004/edukatif.v3i6.1538

kaku. Hal ini penting untuk meningkatkan daya tarik untuk masyarakat luar dalam mengenal kearifan lokal urang Sunda melalui lembaga pendidikan dengan lebih memperkenalkan simbol, bahasa, tata cara perilaku, dan permainan anak Sunda atau kakawihan barudak (Faiz et al., 2021).

Sunda adalah kelompok etnis dominan di Jawa Barat dan kelompok etnis terbesar kedua di Indonesia. Masa kecil sering menjadi situs untuk menanamkan ideologi, termasuk ideologi nasionalis melalui retorika anti-Barat. Rebo Nyunda diharapkan mampu membentuk generasi mendatang dengan akar budaya yang kuat dan tidak tergoncang oleh gagasan asing yang negatif (Yulindrasari \& Djoehaeni, 2019).

Dengan perkembangan teknologi yang semakin pesat, pemerintah berupaya menyeimbangkan teknologi masa kini dan kebudayaan sunda, agar generasi siswa zaman sekarang tidak melupakan kearifan lokal budayanya yaitu budaya sunda. Program Bandung Masagi mendekatkan peserta didik kepada pendidikan karakter. Berdasarkan misi pengembangan Program Bandung Masagi adalah untuk memfasilitasi perkembangan seluruh pelajar kota Bandung dalam mengembangkan potensinya dan mewujudkan generasi yang berakhlakul karimah, mencintai dan memiliki keterampilan budaya sunda, memiliki kepedulian terhadap pelestarian dan menjaga lingkungan bagi keberlangsungan kehidupan, serta mewujudkan karakter siswa yang peduli dan cinta tanah air (Kurniawan, n.d.) Tujuan Program Bandung Masagi adalah mewujudkan karakter pelajar Bandung masagi yaitu generasi yang jujur, tangguh, peka, peduli, berani, tekun, kritis, inisiatif, kreatif, ramah, bertanggung jawab yang tercermin dari sikap religius, kearifan terhadap budaya sendiri, kecintaan lingkungan, kecintaan terhadap bangsa dan negaranya berlandaskan filosofi silih asih, silih asah, silih asuh dan silih wawangi. Program Bandung Masagi merupakan panduan sistematis yang terdiri dari empat komponen program yaitu: komponen religi, budaya sunda, lingkungan, dan bela negara sebagai wahana pembentukan karakter pelajar Bandung masagi berlandaskan filosofi sunda silih asih, silih asah,silih asuh dan silih wawangi. Setiap komponen pada Program Bandung Masagi dikembangkan sebagai wahana untuk pembentukan karakter pelajar bandung masagi yang direpresentasikan melalui: (1) kesadaran akan nilai-nilai religi sehingga terwujud siswa yang berakhlakul karimah, (2) kecintaan dan keterampilan terhadap budaya sunda. (3) kepedulian terhadap pelestarian dan menjaga lingkungan bagi kelangsungan hidup. (4) kecintaan dan kepedulian terhadap tanah air (Dinas pendidikan, 2016).

Komponen Program Bandung Masagi terdiri dari kompenen religi, budaya sunda, lingkungan, dan bela negara. Berikut tabel komponen Program Bandung Masagi pada budaya sunda:

Tabel. 1

\begin{tabular}{|c|c|c|c|c|}
\hline Komponen & $\begin{array}{c}\text { Nama } \\
\text { Program }\end{array}$ & $\begin{array}{c}\text { Strategi } \\
\text { Pelaksanaan }\end{array}$ & Tujuan & $\begin{array}{c}\text { Nilai yang } \\
\text { Dikembangkan }\end{array}$ \\
\hline Budaya Sunda & Rebo Nyunda & Pembiasaan & $\begin{array}{l}\text { Melestarikan } \\
\text { nila-nilai luhur } \\
\text { budaya sunda } \\
\text { dalam kehidupan } \\
\text { sehari-hari. }\end{array}$ & $\begin{array}{c}\text { Silih asah, silih } \\
\text { asih, silih asuh, } \\
\text { silih wawangi: } \\
\text { jujur, peka, } \\
\text { peduli, berani, } \\
\text { tekun, } \\
\text { kritis,inisiatif, } \\
\text { kreatif, ramah, } \\
\text { bertanggung } \\
\text { jawab. }\end{array}$ \\
\hline
\end{tabular}

Urang Bandung harus nyunda, dalam artian mencintai budaya sunda sebagai bagian dari budaya nasional. Di tengah derasnya gempuran budaya asing, maka orang Bandung harus menjadi bagian dari unsur bangsa yang ikut mempertahankan budaya bangsa termasuk budaya daerah. Istilahnya, wawasan boleh global, tapi aksi atau jati diri lokal. Implementasinya bisa dalam bentuk yang beragam. Misalnya dengan berbahasa sunda ketika berbicara, menggunakan pakaian adat sunda, mempelajari seni sunda, melestarikan kaulinan 
5040 Kearifan Lokal Sunda dalam Kegiatan Rebo Nyunda dan Potensinya untuk Tujuan Wisata PendidikanImas Kurniawaty, Asep Dahliyana, Aiman Faiz

DOI: https://doi.org/10.31004/edukatif.v3i6.1538

budak sunda, bersikap, dan berperilaku nyunda, dan sebagainya. Untuk mendukung program Pemerintah Kota Bandung, setiap hari rabu sangat rutin mengadakan kegiatan Rebo Nyunda, dengan menjaga dan memelihara budaya bangsa yaitu budaya sunda. Kegiatan berupa kaulinan urang sunda, bazar makanan khas sunda, karawitan, menggunakan pakaian adat sunda dan banyak kearifan lokal budaya sunda. Guru, staf sekolah dan tentunya peserta didik semua ikut mendukung juga melaksanakan kegiatan tersebut. Kegiatan ekstrakulikuler pun bisa berbasis kearifan local dari program ini, seperti angklung dan Pencak Silat juga merupakan perwujudan dalam memelihara budaya Jawa Barat (Dinas pendidikan, 2016).

Beberapa sekolah di kota Bandung sudah ikut berpartisipasi dalam program Rebo Nyunda, pada lingkungan sekolah terdapat lembaga sosialisasi yang telah dikembangkan bahkan sebelum adanya program Rebo Nyunda, salah satunya dengan mengembangkan kebudayaan Sunda seperti ekstrakurikuler angklung dan pencak silat, acara-acara OSIS, seperti Mojang Jajakan dan Festival Budaya. Selain itu, sekolah pun mengadakan acara khusus di lingkungan SMA Pasundan 1 Bandung untuk launching program Rebo Nyunda. (Choerunisa \& Dahliyana, 2016) Bahkan di tahun 2019, Sekolah Menengah Atas (SMA) Pasundan 1 Bandung menerima kunjungan siswa dari Kalimantan Timur (Kaltim) yang mengikuti program Siswa Mengenal Nusantara (MSN) Tahun 2019 di aula sekolah, Jln. Balonggede No. 28, Kota Bandung, Jumat (16/8/2019). Seluruh siswa Kaltim diperkenalkan dengan budaya Sunda melalui penampilan ekstrakurikuler kesenian yang ada di SMA Pasundan 1 Bandung. Di antaranya, penampilan angklung, tarian daerah, dan sinden. Siswa daerah Kaltim pun mengenalkan budaya daerahnya melalui seni tari khas suku Dayak (Dinas pendidikan, 2016).Hal ini merupakan perwujudan dari program rebo nyunda ini berpotensi untuk menjadi tujuan wisata Pendidikan dalam mengenalkan dan melestarikan budaya dan nilai-nilai kehidupan sunda pada tamu/pendatang dari luar Jawa Barat.

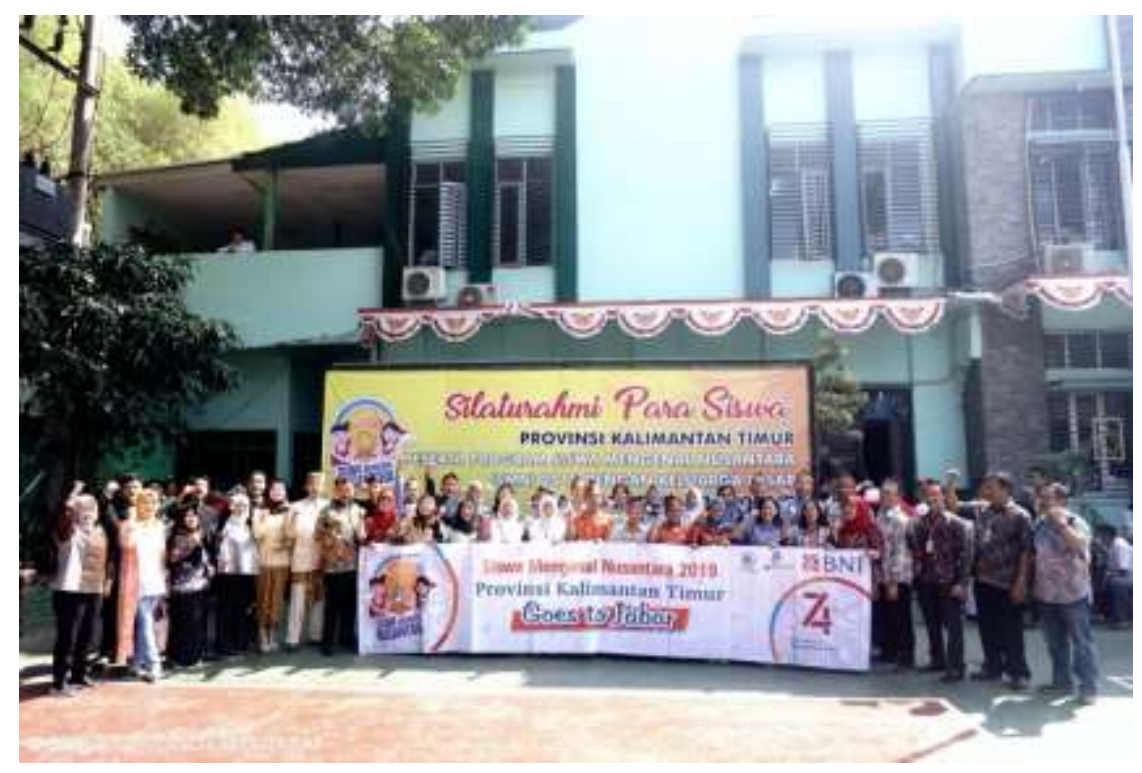

Gambar 1: SMA Pasundan 1 Bandung menerima kunjungan siswa dari Kalimantan Timur yang mengikuti program Siswa Mengenal Nusantara 2019 (16/8/2019)

Sumber: disdik.jabarprov.go.id

\section{KESIMPULAN}

Penelitian ini menggambarkan pentingnya menjaga kearifan lokal yang melekat pada falsafah hidup, sikap dan pedoman perilaku masyarakat dari berbagai ancaman dinamika kehidupan yang mampu memberikan pengalaman yang menarik dan interaktif, pengetahuan baru, dan rasa kepuasan wisata. Upaya penguatan kearifan lokal dilakukan melalui program Rebo Nyunda sebagai kegiatan mengenalkan peserta 
5041 Kearifan Lokal Sunda dalam Kegiatan Rebo Nyunda dan Potensinya untuk Tujuan Wisata PendidikanImas Kurniawaty, Asep Dahliyana, Aiman Faiz

DOI: https://doi.org/10.31004/edukatif.v3i6.1538

didik tentang tradisi dan budaya Sunda. Berhubung program Rebo Nyunda erat kaitannya dengan budaya Sunda, secara tidak langsung mampu memberikan informasi penting dalam perencanaan lanskap wisata budaya kreatif di lembaga pendidikan. Tahapan kebijakan program Rebo Nyunda sebagai acara untuk tujuan wisata edukasi, sebagai berikut: 1) pemerintah menjalankan perannya dengan mengelola sumber daya manusia, prasarana, sarana, dan ketersediaan sumber daya pendukung yang dibutuhkan dalam pengembangan program Rebo Nyunda sebagai destinasi wisata pendidikan; 2) erancang strategi pengembangan pariwisata terkait institusi pendidikan yang terkait dengan kearifan lokal untuk memberikan wawasan kepada peserta didik; 3) melaksanakan kajian teoritis dan praktis model pengelolaan sekolah dan pengembangan pariwisata dengan kearifan lokal yang tepat dan benar dalam pendidikan bagaimana mengamalkan kehidupan masyarakat Sunda dalam kehidupan dan masyarakat; 4) menawarkan kurikulum pariwisata terutama yang berfokus pada persiapan siswa yang melibatkan nilai dengan kompetensi untuk mengambil banyak masalah etika dalam pariwisata dan secara efektif menavigasi pertemuan moral yang muncul dalam dunia pariwisata; 5) sekolah dapat menambahkan tradisi budaya yang relatif masih digunakan seperti makanan, bahasa, dan permainan khas Sunda selain pakaian yang dibutuhkan; 6) Harus disusun buku pegangan literasi siswa yang berisi kearifan lokal Sunda; 7) partisipasi masyarakat untuk mengemas variasi atraksi, seperti wisata edukasi yang mengajarkan keterampilan.

\section{DAFTAR PUSTAKA}

Choerunisa, K., \& Dahliyana, A. (2016). Internalisasi Nilai Kebudayaan Sunda Dalam Program Rebo Nyunda Di Kota Bandung. Sosietas, 6(2). Https://Doi.Org/10.17509/Sosietas.V6i2.4234

Creswell, J. W. (2010). Research Design Qualitative Approach. London Publication. Lesson In Personal Change. A Fireside Book.

Darmadi, H. (2018). Educational Management Based On Local Wisdom (Descriptive Analytical Studies Of Culture Of Local Wisdom In West Kalimantan). JETL (Journal Of Education, Teaching And Learning), 3(1), 135. Https://Doi.Org/10.26737/Jetl.V3i1.603

Detiknews. (N.D.). Mendikbud Jadikan Bandung Masagi Percontohan Pendidikan Karakter Di Indonesia. Detiknews. Https://News.Detik.Com/Berita-Jawa-Barat/D-3256440/Mendikbud-Jadikan-BandungMasagi-Percontohan-Pendidikan-Karakter-Di-Indonesia

Dinas Pendidikan. (2016). Buku Panduan Pendidikan Karakter Bandung Masagi SMP.

Faiz, A. (2019). Program Pembiasaan Berbasis Pendidikan Karakter Di Sekolah. PGSD Universitas Muhammadiyah Cirebon, 5(20). Https://Doi.Org/Htps://Doi.Org/10.32534/Jps.V5i2.741

Faiz, A., Kurniawaty, I., \& Purwati. (2020). Eksistensi Nilai Kearifan Lokal Kaulinan Dan Kakawihan Barudak Sebagai Upaya Penanaman Nilai Jatidiri Bangsa. Jurnal Education And Development Institut Pendidikan Tapanuli Selatan, 8(4), 27-30. Https://Doi.Org/Https://Doi.Org/10.37081/Ed.V8i4.2067

Faiz, A., \& Soleh, B. (2021). Implementasi Pendidikan Karakter Berbasis Kearifan Lokal. Jinop (Jurnal Inovasi Pembelajaran), 7(1), 68-77. Https://Doi.Org/10.22219/Jinop.V7i1.14250

Faiz, A., Soleh, B., Kurniawaty, I., \& Purwati. (2021). Tinjauan Analisis Kritis Terhadap Faktor Penghambat Pendidikan Karakter Di Indonesia. Jurnal Basicedu, Volume 5(4), 1766-1777. Https://Doi.Org/Https://Doi.Org/10.31004/Basicedu.V5i4.1014

Hasanah, A., Gustini, N., \& Rohaniawati, D. (2016). Cultivating Character Education Based On Sundanese Culture Local Wisdom. Jurnal Pendidikan Islam, 2(2), 231. Https://Doi.Org/10.15575/Jpi.V2i2.788

Kurniawan, H. (N.D.). Penguatan Pendidikan Karakter Melalui Budaya Lokal “ Masagi .” 2017, 50.

Maryani, E., \& Yani, A. (2016). Local Wisdom Of Kampung Naga In Mitigating Disaster And Its Potencies For Tourism Education. Man In India, 96(12), 4829-4844. 
5042 Kearifan Lokal Sunda dalam Kegiatan Rebo Nyunda dan Potensinya untuk Tujuan Wisata PendidikanImas Kurniawaty, Asep Dahliyana, Aiman Faiz

DOI: https://doi.org/10.31004/edukatif.v3i6.1538

Mawarni, H., Suwandi, S., \& Supriyadi, S. (2019). Local Wisdom In Lawas (Poetry) Ponan Party Ceremony Society Of Sumbawa Nusa Tenggara Barat. International Journal Of English Literature And Social Sciences, 4(2), 241-247. Https://Doi.Org/Doi.Org/10.22161//jels.4.2.8

Mufti, H. A. (2012). Sosialisasi Program Rebo Nyunda Oleh Ridwan Kamil. 53(9), 1689-1699. Https://Doi.Org/Doi.Org/10.1017/CBO9781107415324.004

Saad, Z. I. (2017). Building Tourists Based On Local Wisdom , In Pesisir Selatan Regency. 10, 13-15.

Santosa, A. B., Basuki, Y., \& Puspita, A. M. I. (2019). The Effectiveness Of Local Wisdom-Based Teaching Materials In Enhancing Creative Writing Skills Of Elementary School Students. Journal Of English Language Teaching And Linguistics, 4(3), 349. Https://Doi.Org/10.21462/Jeltl.V4i3.326

Sibarani, R. (2014). Kearifan Lokal (Hakikat, Peran Dan Metode Tradisi Lisan). Asosiasi Tradisi Lisan (ATL).

Singsomboon, T. (2014). Tourism Promotion And The Use Of Local Wisdom Through Creative Tourism Process. IJBTS International Journal Of Business Tourism And Applied Sciences, 2(2), 32-37. Https://Doi.Org/10.1007/S10529-009-0096-0

Strauss, A., Corbin, J. (2009). Dasar-Dasar Penelitian Kualitatif (P. Pelajar (Ed.)).

Suryalaga, H. (1993). Etika Jeung Tatakrama. Geger Sunten.

Yin, K. R. (2002). Studi Kasus Desain Dan Metode. Rajawali Press.

Yulindrasari, H., \& Djoehaeni, H. (2019). Rebo Nyunda: Is It Decolonising Early Childhood Education In Bandung, Indonesia? Journal Of Pedagogy, 10(1), 57-75. Https://Doi.Org/10.2478/Jped-2019-0003

\section{Referensi Online}

(Http://Bandungjuara.Com). (2013).

(Https://Jabar.Tribunnews.Com/2016/07/19/Ini-Harapan-Emil-Soal-Bandung-Masagi-Dalam-KonsepPendidikan-Karakter). (N.D.). 